Ben Sweeting (2015),"Cybernetics of practice", Kybernetes, Vol. 44 Iss 8/9 pp. 1397 - 1405.

\title{
Cybernetics of practice
}

\author{
Ben Sweeting
}

Architecture, University of Brighton, Brighton, UK

\author{
Abstract \\ Purpose - The purpose of this paper is to explore ways in which cybernetics leads to \\ distinctive ways of acting.
}

Design/methodology/approach - Paralleling von Foerster's argument that it makes more sense to speak of the cybernetics of epistemology than the epistemology of cybernetics, the author argues that cybernetics is not one form of practice amongst others but an account of what it is to practice, understood as where we relate how we act to how we understand so that each informs the other. The author explores the potential difference that adopting this understanding of practice makes in practice and shows its significance by establishing connections between the eponymous cybernetic example of steering and questions regarding teleology in ethics.

Findings - While all practice is cybernetic in the sense of involving a relationship between understanding and acting, the relationship between cybernetics and practice is not a neutral one. Understanding practice in cybernetic terms enables us to pursue goods internal to the practice, which, in turn, makes a difference to how we act.

Practical implications - The author argues that how we understand the relation between our understanding and our acting (our theories of theory and practice) leads to significant differences of action in practice.

Originality/value - The author argues that cybernetics has non-neutral, and ethically significant, consequences in practice that are beyond the application of cybernetics to practice or the advantages of adopting explicitly conversational ways of acting.

Keywords: Design, Ethics, Cybernetics, Epistemology, Purpose, Theory and practice Paper type: Conceptual paper

\section{Cybernetics and practice}

While cybernetics is primarily a way of understanding - of thinking, theorising or explaining it is also closely related to how we act. There are many aspects to this. It is particularly evident in the performative quality of some cybernetic research, such as that of Ashby, Walter and Pask, who played out their ideas using physical experimental devices (a quality which has been emphasised by Pickering, 2010). There are similarities between this and current 
thinking in art and design about practice-based research and this is one basis of the various collaborations between cybernetics and disciplines such as art and design, as explored in the 2010 Cybernetics: Art, Design, Mathematics - A Meta Disciplinary Conversation conference of the American Society for Cybernetics (ASC) in Troy (Glanville, 2012; Glanville and Sweeting, 2011). Indeed, there is a substantial relation between cybernetics and design in terms of the circular, conversational structure that they both share (see for instance: Dubberly and Pangaro, 2007; Fischer, 2014; Glanville, 2007a, c, 2009; Jachna, 2011; Jonas, 2007; Krippendorff, 2007; Sweeting, 2011). Glanville has developed this analogy to the extent that he claims that "cybernetics is the theory of design and design is the action of cybernetics" (Glanville, 2007c, p. 1178) and I return, therefore, to the example of design again below in order to explore the relation between cybernetics and practice.

Underlying these different examples is the way that the epistemology of cybernetics challenges the boundary between how we understand and how we act, and so between theory and practice. First, as is reflected on in second-order cybernetics, theory is something that we construct and so is, itself, a form of practice. Second, cybernetics understands our explanations of our actions (understanding, theory) as integrated together with our acting in a circular relationship, as explored by the ASC's 2013 Acting-Learning-Understanding conference in Bolton (Glanville, 2014; Glanville et al., 2014). This circularity between understanding and action is exemplified in the eponymous cybernetic example of steering a ship, where the steersman's understanding of the effects of his or her action informs how he or she continues to act. This contrasts with where we try to apply theory linearly to practice or, vice versa, where we fail to situate theory in such a way that it can lead to new ways of acting.

Recent ASC conferences have reflected on these themes, drawing on the idea, as proposed by Mead (1968) to the inaugural meeting of the ASC, that a cybernetic society be run according to cybernetic insights. While the principle legacy of Mead's paper was the epistemological turn of second-order cybernetics - the idea that cybernetics be applied to itself, as developed by von Foerster (1974/1995, 2003a) and others - the ASC has returned to the original context of Mead's question to consider how cybernetics might be practiced cybernetically [1]. This question has been explored in the format as well as the content of the conferences, which have been structured in a conversational, and so cybernetic, manner. This format has offered advantages as an alternative to the traditional paper delivery model [2]. The constrained and predetermined nature of paper presentations, often across several parallel sessions, can tend to restrict the possibilities for exchange, research and learning during the conference itself (Glanville, 2011; Pask, 1979). The conversational format, by contrast, allows papers to develop in response to discussions and leads to the composition of new research questions, which can be worked on collaboratively during the conference. While these advantages are applicable across academic practice, the conversational format has further significance in the context of cybernetics, in that participants can explore cybernetic ideas by acting them out in the performance of the conference itself. This has parallels with 
the performative experimentation of Pask and others and, also, with the way that, in design education, the conversational structure of studio teaching (as described for instance by Schön, 1983/1991) is valuable not just because of the pedagogic benefits of "an atmosphere [...] conducive to conversation" (von Glasersfeld, 1992, p. 444) but also as an enactment of the design process, allowing it to be explored.

\section{Acting cybernetically}

While in the context of the ASC conferences, in Pask's research and in design tutorials, a conversational way of acting is primarily an investigation of the topic itself, it offers advantages in any case, such as those I have noted above regarding conference organisation. These are both practical and also ethical: conversational approaches help us deal with complexity, generate new possibilities and, also, in incorporating ethical considerations (for instance, regarding others) into our actions. These aspects are all manifest in the analogy with designing. While the situations in which designers work are full of incomplete and changing requirements such that, as Rittel (1972) describes, they are unresolvable by linear methods, designers approach them as a matter of course, creating new possibilities in so doing (see for instance: Cross, 2007; Gedenryd, 1998; Glanville, $2007 \mathrm{~b}, \mathrm{c})$. That they can do this is largely due to the interactive way in which they work, characterised by Schön (1983/1991) as a "reflective conversation with the situation" (p. 76) and exemplified by the conversations that designers hold with themselves when sketching (Glanville, 2007c). Moreover, this conversational way of working is valuable not just practically but also ethically (Kenniff and Sweeting, 2014; Sweeting, 2014). This is partly through the way that engagement in dialogue with stakeholders is an integral part of the design process rather than something added on to it (as it is sometimes regarded) and, also, even through the sorts of conversations that designers hold with themselves through the use of drawings and models. That is, even in their more internal processes such as sketching, designers put themselves in the place of others by, for instance, "walking through" a plan drawing in order to try to understand how what they are designing will be experienced. In this way, designers consider those absent stakeholders, such as the future users of a building or its passers by, whom they will not be able to meet let alone consult, but who will be affected by what they propose. This thinking "through the eyes of the other", to borrow a phrase which von Foerster (1991) attributed to Frankl, is one of several ways in which cybernetic processes, such as design, may be said to coincide with ethical considerations or even to require them (Glanville, 2004a, 2007c; Poerksen, 2011; von Foerster, 2003b, p. 244, 2003c; von Foerster and Poerksen, 2002).

While this seems to provide a basis for regarding cybernetics as a way of acting to be emulated, there are difficulties with maintaining such a position. First, there is an apparent neutrality to some cybernetic ideas. The radically constructivist epistemology of cybernetics leaves open the possibility of contrasting explanations being equally viable: as von Glasersfeld (1990, p. 19) notes, it "would be perjury for a radical constructivist" to insist that 
their account of epistemology was true. Second, while we can point to the benefits of cybernetic ways of acting, it is not always possible to clearly distinguish those actions that are cybernetic from those that are not. The step in Rosenblueth et al.'s (1943) proto-cybernetic paper "Behaviour, purpose and teleology" that distinguishes those actions that are cybernetic in structure from those that are not is that which asks whether they are intrinsically purposeful, involving circular feedback mechanisms. This step, however, is ambiguous, following from the way that "purpose" can be taken both as a synonym for goal and also as the way of acting towards that goal. The examples which Rosenblueth et al. cite as nonpurposeful (a clock, a roulette wheel, a gun), while not exhibiting "intrinsic purposeful behaviour" (p. 19) in the same way as a servo-mechanism, can be said to be a purpose in themselves (the goal of their designing and making) and can also be used purposefully. While these distinctions can be clarified (this ambiguity is one of the issues raised by Taylor (1950a) and to which Rosenblueth and Wiener (1950) respond), it follows that the distinction between those actions that are cybernetic in their structure from those that are linear depends on how we draw the limits of the system and so, in turn, not just on what we are explaining but, also, on what aspects of it we are trying to explain.

There is a sense that we can explain even the most un-cybernetic and linear of actions in cybernetic terms - even linear coding, as Glanville (2004b, p. 1382) has noted, can be understood as a restricted version of conversation. This is because cybernetics is not merely an account of one epistemology amongst others that might be adopted but of the basis of epistemology itself - that is, its account, while provisional, is not relativist [3]. As von Foerster (2003b) has argued, it makes more sense to speak of the cybernetics of epistemology rather than the epistemology of cybernetics and, similarly, Glanville (2006) has argued, through his analogy between design and cybernetics, that design and cybernetics are at the basis of all human activity: that "to design is to be human, and vice versa" (p. 1). Likewise, cybernetics is not one form of practice amongst others (the practice of cybernetics or the application of cybernetics to practice), but an account of what it is to practice (the cybernetics of practice) and of what distinguishes practice from merely unthinking repetition or sequences of unrelated actions. This is not to say that all practice is equally reflective while coding can be understood as a specifically restricted form of conversation, this restriction brings with it crucial differences - but even the most linear application of theory to practice involves at least some degree of reflective understanding and learning about how this is to be done. Practice is therefore always cybernetic in structure, consisting of a circular relation between how we act and how we explain or understand that action, familiar from examples such as steering, such that our actions are interdependent with how we understand them (see, e.g. Glanville, 2014; Martin, 2011; Schön, 1983/1991).

\section{Teleology and ethics}

That all practice is cybernetic in this sense means that the relation of cybernetics to practice cannot be merely a direct advocacy of those ways of acting that are cybernetic over others

This article is $\odot$ Emerald Group Publishing and permission has been granted for this version to appear here <http://eprints.brighton.ac.uk>. Emerald does not grant permission for this article to be further copied/distributed or hosted elsewhere without the express permission from Emerald Group Publishing Limited. 
which are not. This is not, however, to say that the relationship between cybernetics and practice is a neutral one. In this section I outline one way in which understanding practice in cybernetic terms, as a circular relation between our acting and understanding, leads to significantly different ways of acting.

As Rosenblueth et al. (1943) showed, the circularity of a cybernetic system, such as the relation between action and understanding with which I have characterised practice, allows a purpose to be pursued. Rosenblueth et al. (1943, p. 18) defined purpose as follows:

The term purposeful is meant to denote that the act or behaviour may be interpreted as directed to the attainment of a goal - i.e., to a final condition in which the behaving object reaches a definite correlation in time or in space with respect to another object or event.

As Taylor (1950b) argues, this conception of purpose as striving towards a definite final condition does not account for vague or unsuccessful activities that are still goal-directed although no goal exists, such as "a man groping about in the dark for matches which are not there, but which he erroneously believes to be near at hand" or, alternatively, how "the alchemist can seek the philosopher's stone, the knight can seek the Holy Grail” (p. 329).

While one could answer Taylor's comments in a variety of ways, there is a sense in which they anticipate a richer conception of purpose. This is to see the goal of the targetseeking torpedo, to use Rosenblueth et al.'s (1943) example, not as the ship itself, or even the "apparent focus from which the sound waves emanate" (Rosenblueth and Wiener, 1950, p. 321), but of being on course for the ship. Similarly, in the eponymous cybernetic example of steering, instead of identifying the destination we are steering towards as the goal, defining our action in terms of something external to it, we can equally understand the purpose of steering as staying on a steady course in response to changes in the environment and of learning how to improve at this, and so as internal to our action. This is not to say that if the goals of an action are internal, that it will not also involve external goals or that we must choose between these two sorts of goals. Indeed it is the pursuit of the internal goal of being on course that allows the external goal of the port (and of alternative destinations) to be pursued, while it is the journey to the port that gives the internal goal of steering its relevance and context [4].

Understanding purpose in this sense, the behaviour of the torpedo can be described as purposeful even if the chase goes on indefinitely and there is no final condition, a description which could equally be applied to the knight's quest for the Holy Grail, the alchemist's for the philosopher's stone or the search for absent matches. This is, notably, the sort of purpose that designers pursue: it is not possible to define the conditions at which they aim in advance because new understandings and possibilities, and with them new criteria, are created during the design process as the situation is explored. It follows that designers do not usually attempt to directly fulfil the project brief that they are given at the outset but

This article is $\odot$ Emerald Group Publishing and permission has been granted for this version to appear here <http://eprints.brighton.ac.uk>. Emerald does not grant permission for this article to be further copied/distributed or hosted elsewhere without the express permission from Emerald Group Publishing Limited. 
instead actively put that brief in question, shifting the external goals at which they aim as they explore what follows from them. In this, designing is not dissimilar to the ship example where the steersman, rather than aiming at one preselected port, uses his or her ability to steer (the internal goal of being able to maintain a course) in order to explore different directions and destinations. In this way, design takes the form of an open ended and forward looking search that, as Pickering (2010) has noted, is characteristic of cybernetic practice more generally.

The question of whether the goals of our actions are internal or external to them is an important one in ethical philosophy, distinguishing between two approaches to understanding ethics in terms of teleology: that of, first, the Aristotelian tradition and its revival as virtue ethics by, for instance, Anscombe (1958) andMaclntyre (1981/1985, 1988); and, second, that of consequentialist ethical theories such as utilitarianism. The senses of teleology and the corresponding nature of the telos or goal in each of these are very different. In the Nicomachean Ethics, Aristotle defines the good as the goal at which all things aim (I.1) and goes on to argue that the ultimate human goal be understood as that of eudaemonia (I.7), usually translated as "happiness", "the good life" or "human flourishing", something which is intrinsic to and inseparable from the very action of living. In contrast to this, in consequentialism an ethical action is one that maximises its good consequences according to some way of weighing competing priorities against each other. This understands the goal of action as external to it, with the result that any means could be justified if it achieves the greatest good overall.

While the extrinsic nature of the good in consequentialism opens it up to criticisms, such as those of Anscombe (1958), the intrinsic nature of the good in virtue ethics leaves it with a problem of definition. MacIntyre (1981/1985) defines the good life self-referentially: "the good life for man is the life spent in seeking for the good life for man"; that is, as a form of "quest" (p. 219). In discussing the example of steering a ship, I noted that we can think of the goal of the steering as either the external and fixed goal of the port to which it is travelling or, alternatively, as the internal goal of maintaining and learning to maintain a course, a goal which allows us to take control of the destination we are steering towards. The lack of specificity in Maclntyre's definition, and the corresponding lack of specific moral guidance for which virtue ethics has been criticised (e.g. Louden, 1997, pp. 205-206), is in this sense essential to it. The definition of some specific final end, such as is attempted in consequentialism, would result in the termination of the circularity, and so of the selfreference, and the end of the possibility of pursuing the good life [5].

As part of his wider account, MacIntyre (1981/1985, p. 187) attempts, rather unconvincingly, to distinguish between activities that involve the pursuit of internal goods and those others that do not - arguing, for instance, that whereas architecture involves internal goals, bricklaying does not. Given the circular relationship between acting and understanding that, I have suggested, is a quality of all practice, it does not make sense to draw a distinction in this way. Both architecture and bricklaying, and indeed any practice, can involve the pursuit of internal goods, together with external ones, because the circularity between acting and 
understanding allows an internal purpose to be pursued. The existence of this possibility is, however, no guarantee that internal goals will be pursued: any activity can be reduced to the merely transactional pursuit of external goals where we neglect its internal ones.

The possibility of pursuing internal goals is, therefore, dependent in part on how we understand the relation between our understanding and our acting. Where we optimise our actions against fixed goals, as for instance in consequentialism, we obscure the circularity of practice and so the possibility of pursuing internal goods. This applies also to where we justify ourselves in terms of objectivity, rigidly follow predetermined rules or otherwise apply theory linearly to practice. It is not that, when we act in these ways, we are pursuing an alternative linear form of practice. The circularity between acting and understanding is still there, and we may well adjust the rules we follow or the way we apply our understanding, but we give ourselves little opportunity to learn or to generate new possibilities as we act, with the result that we become predictable and repetitive. In this respect the value of von Foerster's (2003c) invocation that we put ethics into practice rather than into words is not solely a matter of avoiding moralising and taking responsibility. Articulating ethics as a series of moral rules or calculi to then be put into practice obstructs not just our personal responsibility but also the possibility of pursuing internal goals because our actions are rigidly specified in advance.

This is, therefore, one way in which a cybernetic understanding makes a significant difference to how we act. Where we explain practice in terms of the linear application of theory, we obscure the possibility of internal goals. Where we understand practice as a circular relationship between understanding and action, there are always internal goals to pursue. Whether we explain our actions in terms of only external goals, or as also including those which are internal, leads to us placing value differently in the situation and so to significantly different ways of acting. These include the contrasting courses of actions suggested in the same circumstances by consequentialism and virtue ethics and the difference between the sort of architecture or brickwork which have responded only to external goals, such as finishing the job on time or on budget, and that which has also pursued internal goods such as their spatial qualities or craftsmanship. Our understanding of the relation between our understanding and our acting (our theories of theory and practice) makes a difference, therefore, to how we act. That this is the case is, itself, an instance of the circular relation between acting and understanding. That is, when we understand practice in cybernetic terms, and so as a relationship between our acting and our understanding of this acting, then, in turn this understanding has consequences for our acting out of our practicing because, like any other understanding of our acting, it is in cybernetic relation to it.

\section{Notes}

1. As well as in its conferences, the ASC explored this question through a competition, won by Mick Ashby (Glanville, 2012, pp. 197-210). Entries to the competition can be found at: www.asc-cybernetics.org/CofC

2. The point is not that the conversational format is necessarily a better one but that it offers

This article is $\odot$ Emerald Group Publishing and permission has been granted for this version to appear here <http://eprints.brighton.ac.uk>. Emerald does not grant permission for this article to be further copied/distributed or hosted elsewhere without the express permission from Emerald Group Publishing Limited. 
something different.

3. Glanville (2007c, p. 1182) makes an analogy with Newtonian and Einsteinian mechanics: circular causality, like Einsteinian mechanics, is the more general case while linear causality, like Newtonian mechanics, is a still viable but specific limitation.

4. Note that this discussion of internal and external goals is not one that corresponds to a distinction between first- and second-order cybernetics regarding the position of the observer but rather is regarding the qualities of a goal in relation to the actions that pursue it. My argument is therefore along different lines to the points made by Glanville (1997, 2004b).

5. The continuity between the conception of purpose in cybernetics and that in the Aristotelian tradition that I explore here is not surprising. Cybernetics reintroduced questions regarding purpose into scientific debate where they had, with Aristotle, long fallen out of favour to be replaced by more mechanical and linear accounts of cause. While Rosenblueth and Wiener (1950) distance themselves from final causes, understanding purpose in terms of circularity removes the problem of final causes somehow having happened after the event (as noted by Stewart, 2000). As von Foerster (2003c) has put it: "we are all cyberneticians (whether or not we call ourselves such) whenever we justify our actions without using the words 'because of [...],' or 'à cause de [...],' but with the phrase in English 'in order to [...],' which in French is much more Aristotelian, 'à fin de [...]'” (p. 298).

\section{References}

Anscombe, G.E.M. (1958), "Modern moral philosophy", Philosophy, Vol. 33 No. 124, pp. 1-19. doi: $10.1017 /$ S0031819100037943.

Cross, N. (2007), Designerly Ways of Knowing, Birkhäuser, Basel.

Dubberly, H. and Pangaro, P. (2007), "Cybernetics and service-craft: language for behaviorfocused design", Kybernetes, Vol. 36 Nos 9/10, pp. 1301-1317. doi: 10.1108/03684920710827319.

Fischer, T. (2014), "Wiener's refiguring of a cybernetic design theory", IEEE Conference on Norbert Wiener in the 21st Century (21CW), Boston, MA, 24-26 June. doi: 10.1109/NORBERT.2014.6893913.

Gedenryd, H. (1998), How Designers Work: Making Sense of Authentic Cognitive Activities, Vol. 75, Lund University Cognitive Studies, Lund. Available at: http://lup.lub.lu.se/record/18828/file/1484253.pdf (accessed 3 June 2015).

Glanville, R. (1997), "A ship without a rudder”, in Glanville, R. and de Zeeuw, G. (Eds), Problems of Excavating Cybernetics and Systems, BKS+, Southsea, available at: www.univie.ac.at/constructivism/papers/glanville/glanville95-ship.pdf

Glanville, R. (2004a), "Desirable ethics", Cybernetics and Human Knowing, Vol. 11 No. 2, pp. 77-88, available at: www.ingentaconnect.com/content/imp/chk/2004/00000011/00000002/art00007 (accessed 4 June 2015).

Glanville, R. (2004b), "The purpose of second-order cybernetics", Kybernetes, Vol. 33 Nos 
9/10, pp. 1379-1386. doi: 10.1108/03684920410556016.

Glanville, R. (2006), "Design and mentation: Piaget's constant objects", The Radical

Designist, Zero issue, pp. 1-5, available at: www.iade.pt/designist/pdfs/000_05.pdf (accessed 3 June 2015).

Glanville, R. (Ed.) (2007a), "Cybernetics and design", Special Double Issue of Kybernetes, Vol. 36 Nos 9/10, pp. 1153-1589, available at: www.emeraldinsight.com/toc/k/36/9\%2F10 (accessed 3 June 2015).

Glanville, R. (2007b), "Designing complexity”, Performance Improvement Quarterly, Vol. 20 No. 2, pp. 75-96. doi: 10.1111/j.1937-8327.2007.tb00442.x.

Glanville, R. (2007c), "Try again. Fail again. Fail better: the cybernetics in design and the design in cybernetics", Kybernetes, Vol. 36 Nos 9/10, pp. 1173-1206. doi: $10.1108 / 03684920710827238$.

Glanville, R. (2009), "A (cybernetic musing): design and cybernetics", Cybernetics and Human Knowing, Vol. 16 Nos 3/4, pp. 175-186, available at: www.chkjournal.org/administrator/components/com_webjournal/assets/columns/idPu blication_421.pdf (accessed 5 June 2015).

Glanville, R. (2011), "Introduction: a conference doing the cybernetics of cybernetics", Kybernetes, Vol. 40 Nos 7/8, pp. 952-963. doi: 10.1108/03684921111160197. Glanville, R. (Ed.) (2012), Trojan Horses: A Rattle Bag From the 'Cybernetics: Art, Design, Mathematics - A Meta-Disciplinary Conversation' Post-Conference Workshop, Edition echoraum, Vienna.

Glanville, R. (2014), "Acting to understand and understanding to act", Kybernetes, Vol. 43 Nos 9/10, pp. 1293-1300. doi: 10.1108/K-07-2014-0147.

Glanville, R. and Sweeting, B. (Eds) (2011), "Cybernetics: art, design, mathematics - a metadisciplinary conversation: papers from the 2010 conference of the American Society for Cybernetics", Special Double Issue of Kybernetes, Vol. 40 Nos 7/8, pp. 952-1209, available at: www.emeraldinsight.com/toc/k/40/7\%2F8 (accessed 3 June 2015).

Glanville, R., Griffiths, D. and Baron, P. (Eds) (2014), "A circularity in learning”, Special Double Issue of Kybernetes, Vol. 43 Nos 9/10, pp. 1293-1528, available at: www.emeraldinsight.com/toc/k/43/9\%2F10 (accessed 3 June 2015).

Jachna, T. (2011), “Building(s), cybernetically”, Kybernetes, Vol. 40 Nos 7/8, pp. 1055-1065. doi: 10.1108/03684921111160296.

Jonas, W. (2007), "Research through DESIGN through research: a cybernetic model of designing design foundations", Kybernetes, Vol. 36 Nos 9/10, pp. 1362-1380. doi: 10.1108/03684920710827355.

Kenniff, T.-B. and Sweeting, B. (2014), "There is no alibi in designing: responsibility and dialogue in the design process", Opticon1826, No. 16, pp. 1-8. doi: 10.5334/opt.bj.

Krippendorff, K. (2007), "The cybernetics of design and the design of cybernetics", Kybernetes, Vol. 36 Nos 9/10, pp. 1381-1392. doi: 10.1108/03684920710827364. Louden, R.B. (1997), "On some vices of virtue ethics", in Crisp, R. and Slote, M. (Eds), Virtue 
Ethics, Oxford University Press, Oxford, pp. 201-216, Reprinted from: American Philosophical Quarterly, Vol. 21 No. 3, pp. 227-236, 1984.

Maclntyre, A. (1981/1985), After Virtue: A Study in Moral Theory, 2nd corrected ed., Duckworth, London.

Maclntyre, A. (1988), Whose Justice? Which Rationality? Duckworth, London.

Martin, R.J. (2011), "Education as recursive cycles of learning to see through acting and learning to act through seeing: the influence of Heinz von Foerster", Cybernetics and Human Knowing, Vol. 18 Nos 3/4, pp. 123-128, available at: www.ingentaconnect.com/content/imp/chk/2011/00000018/F0020003/art00009 (accessed 3 June 2015).

Mead, M. (1968), “The cybernetics of cybernetics”, in von Foerster, H., White, J.D., Peterson, L.J. and Russell, J.K. (Eds), Purposive Systems, Spartan Books, New York, NY, pp. $1-11$.

Pask, G. (1979), "Against conferences: the poverty of reduction in SOP-science and POPsystems", Proceedings of the Silver Anniversary International Meeting of Society for General Systems Research, SGSR, Washington, DC, August, 1979, pp. xii-xxv, available at: http://pangaro.com/pask/paskagainstconferences+sopscience.pdf (accessed 3 June 2015).

Pickering, A. (2010), The Cybernetic Brain: Sketches of Another Future, University of Chicago Press, Chicago, IL.

Poerksen, B. (2011), "Ethics of enabling ethics", Cybernetics and Human Knowing, Vol. 18 Nos 3/4, pp. 143-149, available at: www.ingentaconnect.com/content/imp/chk/2011/00000018/F0020003/art00013 (accessed 3 June 2015).

Rittel, H. (1972), "On the planning crisis: systems analysis of the 'first and second generations"', Bedriftskonomen, Vol. 8, pp. 390-396.

Rosenblueth, A. and Wiener, N. (1950), "Purposeful and non-purposeful behavior", Philosophy of Science, Vol. 17 No. 4, pp. 318-326, available at: www.jstor.org/stable/185931 (accessed 3 June 2015).

Rosenblueth, A., Wiener, N. and Bigelow, J. (1943), "Behavior, purpose and teleology", Philosophy of Science, Vol. 10 No. 1, pp. 18-24, available at: www.jstor.org/stable/184878 (accessed 3 June 2015).

Schön, D.A. (1983/1991), The Reflective Practitioner: How Professionals Think in Action, Arena, Farnham.

Stewart, D.J. (2000), "An essay on the origins of cybernetics", available at: www.hfr.org.uk/cybernetics-pages/origins.htm (accessed 3 June 2015).

Sweeting, B. (2011), "Conversing with drawings and buildings: from abstract to actual in architecture", Kybernetes, Vol. 40 Nos 7/8, pp. 1159-1165. doi: 10.1108/03684921111160386.

Sweeting, B. (2014), "Architecture and undecidability: explorations in there being no right 
answer - some intersections between epistemology, ethics and designing architecture, understood in terms of second-order cybernetics and radical constructivism", PhD Thesis, The Bartlett, UCL, London, available at: https://iris.ucl.ac.uk/iris/publication/972511/1 (accessed 3 June 2015).

Taylor, R. (1950a), "Comments on amechanistic conception of purposefulness", Philosophy of Science, Vol. 17 No. 4, pp. 310-317, available at: www.jstor.org/stable/185930 (accessed 3 June 2015).

Taylor, R. (1950b), "Purposeful and non-purposeful behavior: a rejoinder", Philosophy of Science, Vol. 17 No. 4, pp. 327-332, available at: www.jstor.org/stable/185932 (accessed 3 June 2015).

von Foerster, H. (Ed.) (1974/1995), Cybernetics of Cybernetics: Or, The Control of Control and the Communication of Communication, 2nd ed., Future Systems, Minneapolis, MN.

von Foerster, H. (1991), "Through the eyes of the other", in Steier, F. (Ed.), Research and Reflexivity, Sage, London, pp. 63-75.

von Foerster, H. (2003a), "Cybernetics of cybernetics", Understanding Understanding: Essays on Cybernetics and Cognition, Springer-Verlag, New York, NY, pp. 283-286, Reprinted from: Krippendorff, K. (Ed.) (1979), Communication and Control, Gordon and Breach, New York, NY, pp. 5-8.

von Foerster, H. (2003b), "Cybernetics of epistemology", Understanding Understanding: Essays on Cybernetics and Cognition, Springer-Verlag, New York, NY, pp. 229-246, Reprinted from: Kiedel, W.D., Handler, W. and Spring, M. (Eds) (1974), Kybernetic und Bionik, Oldenburg, Munich, pp. 27-46.

von Foerster, H. (2003c), "Ethics and second-order cybernetics", Understanding Understanding: Essays on Cybernetics and Cognition, Springer-Verlag, New York, NY, pp. 287-304, Reprinted from: Ray, Y. and Prieur, B. (Eds) (1991), Systèms, Ethique, Perspectives en thérapie familiale, ESF editeur, Paris, pp. 41-55.

von Foerster, H. and Poerksen, B. (2002), Understanding Systems, trans by Leube, K., Kluwer Academic, New York, NY.

von Glasersfeld, E. (1990), "An exposition of constructivism: why some like it radical", Journal for Research in Mathematics Education Monograph, Vol. 4, pp. 19-29. doi: $10.2307 / 749910$.

von Glasersfeld, E. (1992), "Guest editorial”, Educational Studies in Mathematics, Vol. 23 No. 5, pp. 443-444. doi: 10.1007/bf00571466.

\section{Acknowledgement}

This paper develops ideas from the author's recently completed $\mathrm{PhD}$ research at the Bartlett, UCL, which was funded by an AHRC Doctoral Scholarship and supervised by Neil Spiller and Ranulph Glanville. 